\title{
Coming Home: Health Status and Homelessness Risk of Older Pre-release Prisoners
}

\author{
Brie A. Williams, $M D^{1,2}$, James McGuire, PhD ${ }^{3}$, Rebecca G. Lindsay, $M S^{4,5}$, \\ Jacques Baillargeon, $\mathrm{PhD}^{6}$, Irena Stijacic Cenzer, $M A^{1,2}$, Sei J. Lee, $\mathrm{MD}^{1,2}$, \\ and Margot Kushel, $\mathrm{MD}^{7}$
}

\begin{abstract}
'Division of Geriatrics University of California, San Francisco, San Francisco, CA, USA; ${ }^{2}$ San Francisco VA Medical Center Health Services Research and Development Research Enhancement Award Program, San Francisco, CA, USA; ${ }^{3}$ Veterans Health Administration, Healthcare for Reentry Veterans Program, Durham, NC, USA; ${ }^{4}$ San Francisco School of Medicine University of California, San Francisco, CA, USA;

${ }^{5}$ University of California, Berkeley, CA, USA; ${ }^{6}$ Department of Preventive Medicine and Community Health and the Division of Epidemiology, Correctional Managed Care University of Texas Medical Branch, Galveston, TX, USA; ${ }^{7}$ Division of General Internal Medicine University of California, San Francisco, San Francisco, CA, USA.
\end{abstract}

BACKGROUND: Older adults comprise an increasing proportion of the prison and homeless populations. While older age is associated with adverse post-release health events and incarceration is a risk factor for homelessness, the health status and homelessness risk of older pre-release prisoners are unknown. Moreover, most post-release services are geared towards veterans; it is unknown whether the needs of non-veterans differ from those of veterans.

OBJECTIVE: To assess health status and risk of homelessness of older pre-release prisoners, and to compare veterans with non-veterans.

DESIGN/PARTICIPANTS: Cross-sectional study of 360 prisoners ( $\geq 55$ years of age) within 2 years of release from prison using data from the 2004 Survey of Inmates in State and Federal Correctional Facilities.

MAIN MEASURES: Veteran status, health status (based on self-report), and risk of homelessness (homelessness before arrest).

KEY RESULTS: Mean age was 61 years; 93.8\% were men and $56.5 \%$ were white. Nearly $40 \%$ were veterans, of whom $77.2 \%$ reported likely VA service eligibility. Veterans were more likely to be white and to have obtained a high school diploma or GED. Overall, 79.1\% reported a medical condition and $13.6 \%$ reported a serious mental illness. There was little difference in health status between veterans and non-veterans. Although 1 in 12 prisoners reported a risk factor for homelessness, the risk factors did not differ according to veteran status.

CONCLUSIONS: Older pre-release prisoners had a high burden of medical and mental illness and were at risk for post-release homelessness regardless of veteran status. Reentry programs linking pre-release older prisoners to medical and psychiatric services and to homelessness prevention programs are needed for both veterans and non-veterans.

Received September 21, 2009

Revised January 19, 2010

Accepted May 1, 2010

Published online June 8, 2010
KEY WORDS: health status; homelessness risk; pre-release prisoners; older prisoners.

J Gen Intern Med 25(10):1038-44

DOI: $10.1007 / \mathrm{s} 11606-010-1416-8$

(C) The Author(s) 2010. This article is published with open access at Springerlink.com

\section{BACKGROUND}

The United States has the highest incarceration rate of any industrialized country, with 1 in 100 American adults incarcerated in 2008. ${ }^{1}$ Longer sentences and reductions in discretionary parole have led to an increased proportion of older prisoners ( $\geq 55$ years of age). ${ }^{1-3}$ In $2008,4.1 \%$ of US prisoners were aged 55 or older, ${ }^{4}$ and substantial increases in the number of older prisoners are expected. ${ }^{1-3,5}$ The vast majority of prisoners (97\%) eventually return to the community, ${ }^{6}$ typically with no health insurance, limited employment prospects, and insufficient finances. ${ }^{7}$ Most prisoners are released with a nominal amount of "gate money" (generally 50-100 dollars) and a bus ticket, and half of state correctional departments provide only a 1-2 week supply of medication. ${ }^{7}$ Those eligible for government benefits such as Medicaid, Medicare, and social security income must wait up to 3 months for reinstatement. ${ }^{8-10}$ Older prisoners are far less likely than younger prisoners to be reincarcerated after release. ${ }^{11,12}$ Compared to younger prisoners, older prisoners have higher rates of chronic medical conditions and a higher risk of post-release death, ${ }^{2,13,14}$ yet little is known about the health status of older prisoners awaiting release.

Older prisoners may also face challenges to successful community reentry that compound health problems. ${ }^{17,18}$ Many newly released prisoners confront difficulties with employment and housing, ${ }^{15}$ and up to half of the nation's homeless have a history of incarceration. ${ }^{15,16}$ Although the US homeless population has aged over the past several decades, ${ }^{19}$ and homelessness is associated with increased morbidity, mortality and acute health care utilization, ${ }^{20-25}$ the risk of post-release homelessness among older adults has not been evaluated. Such information would be valuable since coordinated treatment programs can improve health outcomes for homeless adults. ${ }^{22}$ 
Because veterans comprise about $10 \%$ of the prison population $^{26}$ and one-third of the homeless population, ${ }^{27}$ the Department for Veterans Affairs has spearheaded several nationwide initiatives to help meet the health care and housing needs of veterans being released from prisons. ${ }^{28,29}$ However, services for non-veteran released prisoners are poorly established and are available only on a state-by-state basis. ${ }^{6,30}$ It is unclear if the reentry needs of non-veterans differ from those of veterans, raising the question of whether similar interventions should be targeted to non-veterans. We assessed and compared the health status and risk of homelessness among older veteran and nonveteran prisoners who were within 2 years of release.

\section{METHODS}

\section{Study Design and Sample}

We conducted a cross-sectional study of 360 prisoners, aged 55 or older, who were within 2 years of release from a US federal or state prison using data from the 2004 Survey of Inmates in State and Federal Correctional Facilities (SISFCF). The SISFCF targets a nationally representative, random sample of US prisoners who participate in confidential interviews conducted by the Census Bureau for the Bureau of Justice Statistics (BJS). ${ }^{31}$ The self-report medical questions were developed by BJS from health questions in other national health surveys. ${ }^{32}$ We included prisoners within 2 years of release to characterize the health status and risk of homelessness of older adults who would soon reenter the community. Consistent with prior literature, we defined "older" prisoners as those who were $\geq 55$ years to reflect the increased and premature burden of illness and disability occurring among prisoners in comparison to non-prisoners. ${ }^{2,3,33,34}$

Overall, 14,499 prisoners from 287 state prisons and 3,686 prisoners from 39 federal prisons were randomly selected to participate in the 2004 SISFCF. The response rate was $89 \%$ for state and $84 \%$ for federal prisoners. ${ }^{31}$ Of 18,185 participants, $974(5.35 \%)$ were $\geq 55$ years of age. Among these older prisoners, $37.0 \%$ were within 2 years of anticipated release, resulting in a final sample size of 360 .

\section{Measures}

Health Status. Health status was based on self-report of 11 chronic medical conditions and 3 categories of serious mental illnesses. The 11 medical conditions included current cancer or paralysis, and current or past diagnosis of hypertension, brain injury or stroke, diabetes, heart problems, kidney problems, arthritis, asthma, cirrhosis, or hepatitis. The three categories of serious mental illnesses included depressive disorders, bipolar disorder, and schizophrenia or another psychotic disorder. We reported post-traumatic stress disorder (PTSD) separately from serious mental illness to be consistent with prior literature. ${ }^{35,36}$ The SISFCF used brief questions to elicit medical histories (e.g., "Have you ever had high blood pressure or hypertension?"). Survey participants who reported a history of cancer or paralysis were asked if the condition was still present. To ascertain mental health status, participants were provided a list of psychiatric disorders and asked if a mental health professional had ever told them they had any of the conditions. To assess disability status, we analyzed responses to four questions: (1) "Do you use a cane, wheelchair, walker, hearing aid, or other aids to help you with your daily activities?" (2) "Do you consider yourself to have a disability?" (3) "Do you have difficulty hearing a normal conversations even when wearing a hearing aid?" (4) "Do you have difficulty seeing ordinary newsprint, even when wearing glasses?" Self-report of medical conditions and disability is well validated in older adults. ${ }^{37-40}$

Risk of Homelessness. Risk of homelessness was primarily defined with two measures: self-report of homelessness at the time of arrest and/or having been homeless at any time in the 12 months prior to arrest. Respondents who answered they were living "on the street or in a homeless shelter" were categorized as homeless. We chose these criteria because a history of homelessness is a strong predictor of post-release homelessness. ${ }^{41}$ In order to better characterize the spectrum of homelessness beyond living on a street or in a shelter, ${ }^{42,43}$ we also examined a history of marginal homelessness: those who reported living in a hotel, motel, or rooming house upon arrest. Because decreased social contacts can confer added homelessness risk, ${ }^{44,45}$ we also identified those who planned to live alone following release.

Veteran Status. We determined veteran status based on the question: "Did you ever serve in the US Armed Forces?" Respondents were categorized according to their service era, self-reported combat status ("During this time did you see combat in a combat or line unit?"), and discharge type (honorable/general with honorable conditions versus other discharge type). However, in the main analyses, we compared all veterans, regardless of discharge type, to all non-veterans because even veterans with dishonorable discharges can sometimes become eligible for VA benefits. ${ }^{46,47}$

Other Demographic Characteristics. We characterized participants according to their sociodemographic characteristics, including age, race/ethnicity, marital status, educational attainment (having a high school diploma or GED vs. not), and pre-incarceration employment. We also characterized criminal history (age at first and current arrest, total arrests, and number of years currently incarcerated). We characterized substance abuse history using CAGE questionnaire data to assess alcohol dependence and the Texas Christian University Drug Screen (TCUDS), which was developed to assess drug dependence in the correctional setting. ${ }^{48}$ By convention, a CAGE alcohol dependency score of $\geq 2$ or a TCUDS score of $\geq 3$ indicates a substance abuse problem. ${ }^{48,49}$

\section{Statistical Analyses}

We examined the differences between veterans and non-veterans according to sociodemographics, employment history, criminal history, health conditions (medical and psychiatric), and risk of homelessness. All reported results were weighted to account for the sampling design in order to obtain nationally representative results. 
Table 1. Sociodemographic, Employment and Criminal History Characteristics of Older Prisoners According to Veteran Status

\begin{tabular}{|c|c|c|c|c|}
\hline & $\begin{array}{l}\text { All prisoners } \\
(\mathrm{N}=360)\end{array}$ & Veterans $^{a}(\mathrm{~N}=142)$ & $\begin{array}{l}\text { Non-veterans } \\
(\mathrm{N}=218)\end{array}$ & $\mathrm{p}$-value \\
\hline \multicolumn{5}{|l|}{ Age, gender, and marital status } \\
\hline Mean age (range), years & $61(55-84)$ & $61(55-84)$ & $60(55-78)$ & 0.07 \\
\hline$\geq 70$ years old $(\%)$ & 7.1 & 14.0 & 2.6 & $<0.001$ \\
\hline Men (\%) & 93.8 & 99.7 & 89.9 & $<0.001$ \\
\hline Married (\%) & 30.4 & 34.4 & 27.7 & 0.003 \\
\hline \multicolumn{5}{|l|}{ Race/ethnicity (\%) } \\
\hline White & 56.5 & 76.7 & 43.3 & $<0.001$ \\
\hline Black or African American & 25.5 & 15.6 & 31.9 & 0.001 \\
\hline Latino/Hispanic & 15.2 & 4.3 & 22.2 & $<0.001$ \\
\hline Other & 2.9 & 3.4 & 2.6 & 0.714 \\
\hline High school diploma or GED (\%) & 53.3 & 71.1 & 41.7 & $<0.001$ \\
\hline \multicolumn{5}{|l|}{ Employment status before arrest (\%) } \\
\hline Any employment & 69.5 & 70.7 & 69.0 & 0.74 \\
\hline Full-time employment ${ }^{\mathrm{c}}$ & 87.2 & 89.9 & 85.4 & 0.18 \\
\hline Monthly income of $<\$ 1,000$ & 38.7 & 33.7 & 42.4 & 0.16 \\
\hline \multicolumn{5}{|l|}{ Risk factors for post-release homelessness (\%) } \\
\hline Homeless at time of arrest & 1.7 & 2.5 & 1.2 & 0.40 \\
\hline Homeless within the year before arrest & 7.4 & 8.7 & 6.6 & 0.50 \\
\hline Marginally housed at time of arrest & 2.3 & 3.5 & 1.5 & 0.23 \\
\hline Any of the above homelessness risk factors & 8.4 & 10.5 & 7.0 & 0.30 \\
\hline \multicolumn{5}{|l|}{ Criminal history } \\
\hline Mean age (range) at first arrest, years & $32(18-64)$ & $30(18-58)$ & $34(18-64)$ & 0.08 \\
\hline Mean number (range) of previous arrests & $3.1(0-35)$ & $2.8(0-30)$ & $3.3(0-35)$ & 0.36 \\
\hline Mean age (range) at current arrest, years & $53(18-79)$ & $53(22-79)$ & $53(18-73)$ & 0.93 \\
\hline Mean years (range) served for current arrest & $7.5(0.1-41.5)$ & $8.2(0.1-41.5)$ & $7.0(0.4-38.6)$ & 0.19 \\
\hline
\end{tabular}

${ }^{a}$ Survey respondents were classified as a veteran if they answered yes to the question: "Did you ever serve in the US armed forces?"

${ }^{b} P$-values were calculated for differences between veterans and non-veterans using t-tests for continuous variables and chi-square analyses for all other variables. All estimates are weight-adjusted to account for the weighted sampling design

${ }^{c}$ Values represent the percentage of respondents working full time among only those respondents reporting any kind of employment

This study was approved by the Committee on Human Research at University of California, San Francisco and the San Francisco VA Medical Center, and was conducted using publicly available, de-identified data. All statistical analyses were performed using STATA software version 10.1 (STATA Corporation, College Station, TX).

\section{RESULTS}

\section{Characteristics of Older Prisoners Within 2 Years of Release}

The mean age of the sample was 61 years (range 55-84). Overall, $7.1 \%$ of the prisoners were $\geq 70$ years of age, $93.8 \%$ were men, $30.4 \%$ were married, $56.5 \%$ were white, and $69.7 \%$ were employed before arrest. Of those who were employed, $87.2 \%$ had full-time jobs. Participants had been incarcerated for an average of 7.5 years and had an average of 3.1 prior arrests (Table 1).

\section{Characteristics According to Veteran Status}

Overall, $142(39.8 \%)$ of the pre-release older prisoners were veterans. The veterans were more likely than non-veterans to be men, married, and to have a high school diploma or GED (Table 1). Veterans were more likely to identify as white $(76.7 \%$ vs. $43.3 \%$ ) and less likely to identify as black (15.6\% vs. $31.9 \%)$ or Latino/Hispanic ( $4.3 \%$ vs. $22.2 \%$ ). Veteran status was not related to employment prior to arrest, monthly income less than $\$ 1,000$ in the month preceding arrest, number of prior arrests, age at first or current arrest, or number of years incarcerated.

The majority of veterans served in the Vietnam-era (69.4\%), between the Korea and Vietnam eras (14.1\%), the Korean era $(9.8 \%)$, or the Pre-Korean era (5.1\%). Thirty-five percent of the veterans had served in active combat, and $77.2 \%$ had received an honorable or general (with honorable conditions) discharge.

\section{Health Status of Older Prisoners}

Nearly $80 \%$ of older pre-release prisoners reported one or more medical conditions with an average of 2.1 (Table 2). The most common medical conditions included hypertension (51.8\%), arthritis (43.6\%), and "heart problems" (34.1\%). Additionally, $30.7 \%$ of the older prisoners reported having a disability, $13.6 \%$ reported at least one serious mental illness, and $8.1 \%$ reported a history of hospitalization in a mental health facility. A quarter had a TCUDS score of $\geq 3$, suggestive of drug dependency, and nearly half $(45.6 \%)$ had a positive CAGE score for alcohol dependency.

\section{Health Status According to Veteran Status}

Veterans and non-veterans reported a similar average number of medical conditions ( 2.1 vs. $2.0, \mathrm{p}=0.55)$, and similar rates of 
Table 2. Clinical Characteristics of Older Prisoners According to Veteran Status

\begin{tabular}{|c|c|c|c|c|}
\hline Characteristic & All prisoners $(\mathrm{N}=360)$ & Veterans $(N=142)$ & Non-veterans $(\mathrm{N}=218)$ & $p$-value ${ }^{c}$ \\
\hline \multicolumn{5}{|l|}{ Medical conditions ${ }^{\mathrm{b}}$} \\
\hline Mean number of medical conditions & 2.1 & 2.1 & 2.0 & 0.55 \\
\hline One or more medical conditions (\%) & 79.1 & 78.1 & 79.7 & 0.75 \\
\hline \multicolumn{5}{|l|}{ Specific medical conditions (\%) } \\
\hline Cancer & 4.4 & 5.6 & 3.7 & 0.43 \\
\hline Paralysis & 2.9 & 4.2 & 2.1 & 0.24 \\
\hline Hypertension & 51.8 & 49.6 & 53.3 & 0.53 \\
\hline Brain injury or stroke & 11.5 & 13.3 & 10.3 & 0.43 \\
\hline Diabetes & 20.4 & 20.1 & 20.6 & 0.91 \\
\hline Heart problems & 34.1 & 37.3 & 31.9 & 0.33 \\
\hline Kidney problems & 15.2 & 17.6 & 13.5 & 0.34 \\
\hline Arthritis & 43.6 & 41.3 & 45.1 & 0.52 \\
\hline Asthma & 13.8 & 19.6 & 10.0 & 0.02 \\
\hline Cirrhosis & 4.3 & 5.8 & 3.3 & 0.28 \\
\hline Hepatitis & 12.6 & 15.5 & 10.7 & 0.23 \\
\hline \multicolumn{5}{|l|}{ Psychiatric disorders } \\
\hline Mean number of serious mental illnesses $(0-3)^{\mathrm{c}}$ & 0.2 & 0.3 & 0.2 & 0.32 \\
\hline One or more serious mental illnesses ${ }^{c}(\%)$ & 13.6 & 14.6 & 13.0 & 0.69 \\
\hline \multicolumn{5}{|l|}{ Specific psychiatric disorders ${ }^{\mathrm{d}}(\%)$} \\
\hline Depressive disorder & 12.9 & 14.3 & 12.1 & 0.57 \\
\hline Bipolar disorder or mania & 4.9 & 7.1 & 3.4 & 0.14 \\
\hline Schizophrenia or other psychotic disorder & 3.0 & 4.0 & 2.3 & 0.41 \\
\hline Post-traumatic stress disorder & 6.3 & 12.6 & 2.3 & $<0.001$ \\
\hline History of mental hospitalization & 8.1 & 9.1 & 7.5 & 0.60 \\
\hline TCU drug dependency score $(\geq 3)^{\mathrm{e}}$ & 25.2 & 26.2 & 24.6 & 0.83 \\
\hline CAGE alcohol dependency score $(\geq 2)$ & 45.6 & 44.4 & 46.5 & 0.78 \\
\hline \multicolumn{5}{|l|}{ Functional/disability status (\%) } \\
\hline Considers self to have a disability & 30.7 & 33.3 & 29.0 & 43.0 \\
\hline Difficulty seeing newsprint with glasses & 20.1 & 20.5 & 19.8 & 0.89 \\
\hline Difficulty hearing with hearing aid & 19.1 & 26.1 & 14.6 & 0.01 \\
\hline Needs aid for daily activities $\mathrm{e}^{\mathrm{e}}$ & 11.5 & 14.7 & 9.5 & 0.17 \\
\hline
\end{tabular}

${ }^{a} P$-values were calculated for differences between veterans and non-veterans using t-tests for continuous variables and chi-square analyses for all other variables. All estimates are weight-adjusted to account for the weighted sampling design

${ }^{b}$ Based on self-reports of 11 chronic medical conditions

${ }^{c}$ Serious mental illness defined as major depressive disorder, bipolar disorder, and schizophrenia or other psychotic disorder

${ }^{d}$ Based on self-reports in which survey respondents answered yes to the question: "Have you ever been told by a mental health professional, such as a psychiatrist or psychologist that you had..."

${ }^{e}$ Aids included but were not limited to a cane, wheelchair, walker, and hearing aid

each medical condition and serious mental illness with the exception of asthma (19.6\% vs. $10.0 \%, \mathrm{p}=0.02)$ and PTSD ( $12.6 \%$ vs. $2.3 \%, \mathrm{p}<0.001)$. Combat veterans were more likely to report PTSD than non-combat veterans $(23.6 \%$ vs. $6.5 \%, \mathrm{p}=$ 0.01). There was no statistically significant difference in PTSD between non-combat veterans and non-veterans $(6.5 \%$ vs. $2.3 \%, \mathrm{p}=0.08$ ). Although there was no relationship between veteran status and alcohol or drug dependency, not all respondents answered all relevant items; $57.3 \%$ of subjects answered all CAGE alcohol dependency questions and $47.1 \%$ answered all TCU drug dependency questions. These percentages did not differ for veterans compared to non-veterans for TCU questions ( $43.6 \%$ vs. $49.4 \%, \mathrm{p}=0.32$ ) but did differ for CAGE questions $(64.7 \%$ vs. $52.5 \%, \mathrm{p}=0.04)$. Veterans and non-veterans were equally likely to consider themselves to have a disability ( $33.3 \%$ vs. $29.0 \%, p=0.43$ ). However, veterans were more likely to report difficulty hearing $(26.1 \%$ vs. $14.6 \%$, $\mathrm{p}=0.01)$.

\section{Risk of Homelessness According to Veteran Status}

Overall, $8.4 \%$ of participants reported at least one of the homelessness risk factors, including being homeless at some point during the year prior to arrest (7.4\% of respondents), living on the street or in a homeless shelter upon arrest (1.7\%), and living in a motel, hotel, or rooming house upon arrest $(2.3 \%)$ (Table 1$)$. These experiences were similar for veterans and non-veterans. Older veterans were not more likely than non-veterans to expect to live alone after release $(31.6 \%$ vs. $24.3 \%, \mathrm{p}=0.16)$.

\section{DISCUSSION}

As the American population ages, the number of incarcerated and homeless older adults is increasing rapidly. ${ }^{1-3,19}$ We found that older veteran and non-veteran prisoners who were within 2 years of release had a similar burden of medical and psychiatric conditions, and an equal number of risk factors for homelessness.

Appropriate targeting of community-based medical services to the growing number of newly released older prisoners is hampered by inadequate information about their health needs. ${ }^{17}$ A survey of returning prisoners of all ages showed that one-third of those with physical or mental health conditions used emergency room care and one-fifth were 
hospitalized within 8-10 months after release. ${ }^{50}$ Another survey found that most older prisoners had fears about their post-incarceration health. ${ }^{18}$ Former prisoners have a 12.7-fold increased risk of death in the 2 weeks following release (even excluding seriously ill prisoners granted compassionate medical release); the most common causes of death for those over age 45 are cardiovascular disease and cancer. ${ }^{14}$ We found that nearly $80 \%$ of older pre-release prisoners in our sample reported at least one chronic medical condition (average of 2.1) and that the rates of many medical conditions exceeded those reported in the community. ${ }^{51}$ These findings highlight the importance of pre-release health care planning for older prisoners.

The prevalence of serious mental illness in older community-dwelling adults is $15 \%-20 \% .{ }^{35}$ A current or past history of serious mental illness was reported by $13.6 \%$ of our sample, similar to rates reported among older prisoners in Texas (11.0\%), ${ }^{36}$ Tennessee (16.0\%), ${ }^{35}$ and Utah (13.6\%). ${ }^{35}$ The actual proportion of our sample burdened with significant mental illness is undoubtedly higher than $13.6 \%$ because PTSD was excluded from the "serious mental illness" category. This exclusion is the result of an operational definition created to maintain consistency and comparability with other studies and is not intended to imply that PTSD is not a serious mental illness. There is a complex relationship among mental illness, homelessness, and incarceration, and a heightened risk of both recidivism and homelessness among released prisoners with mental illness has been observed. ${ }^{36,52,53}$ Additionally, homeless adults with mental illness and an incarceration history have a higher likelihood of experiencing long-term homelessness than those without mental illness. ${ }^{54}$ These findings underscore the importance of providing linkages to community-based mental health services for older released prisoners.

Because of the association between homelessness and increased acute health care utilization and mortality, ${ }^{20-25}$ homelessness prevention strategies have received increasing attention. ${ }^{44}$ A history of incarceration is a risk factor for homelessness, ${ }^{41,44,55}$ and between $6.3 \%$ and $11.4 \%$ of prisoners of all ages use homeless shelters following release. ${ }^{41}$ At least $8.4 \%$ of our sample was at risk for homelessness (based on a prior history of homelessness) and more than a quarter expected to live alone following release. These findings suggest that expanded efforts to secure housing for pre-release older prisoners are warranted.

Although pre-release health care and homelessness prevention planning for all older prisoners is needed, wellestablished and coordinated programs are typically available only to veterans. In 2001, Congress mandated that the Department of Veterans Affairs collaborate with the Department of Labor and the Bureau of Prisons to assist veterans during reentry. ${ }^{28}$ This collaboration culminated in the Incarcerated Veterans Transition Program in 2003, a demonstration program providing incarcerated veterans with connections to housing, health care, training, and employment. ${ }^{56}$ The Healthcare for Reentry Veterans Program, implemented in 2007, has provided outreach and reentry services to over 12,000 veterans in 451 state and federal prisons through June of $2009 .{ }^{57}$ Our study showed that $77 \%$ of pre-release older prisoners who were veterans reported military discharges with conditions likely to make them eligible for VA services. In addition, while veterans comprise about $10 \%$ of the state prison population, ${ }^{26}$ nearly $40 \%$ of our sample of older prisoners were veterans. This highlights the importance of the VA's outreach efforts for this segment of the incarcerated population.

Conversely, $60 \%$ of our sample of older prisoners were nonveterans, underscoring the importance of developing national transition programs for non-veterans for whom existing services are limited. ${ }^{58}$ While non-veterans on parole may receive reentry assistance via a parole officer or formal parole programs, such services are diminishing with increasing non-parole releases and parole officer caseloads. ${ }^{58}$ Although the Serious and Violent Offender Reentry Initiative, established in 2003 , provided more than $\$ 100$ million to local reentry program development, the programs only focused on prisoners aged 35 and younger. ${ }^{30,59}$

Although coordinated reentry programs for non-veteran older prisoners are lacking, we found that rates of poor health status and risk of homelessness were just as high among this group as among veterans. Unfortunately, most states terminate Medicaid, Medicare, and Social Security Disability Income eligibility during incarceration, ${ }^{8-10}$ and reinstituting coverage can take up to 3 months. ${ }^{8,9}$ Given the high costs of emergency department services and the high risk of homelessness, all pre-release older prisoners should receive assistance with securing housing, medical care, and reinstatement of benefits, and should be screened for eligibility for VA services.

A strength of our study was that it included a random, nationally representative sample of US prisoners. Limitations included the use of self-reported data, although the majority of studies have found relatively strong agreement between self-report and medical record validation of major medical conditions in older adults. ${ }^{37-40}$ A validation of the medical questions in the SISFCF did identify some underreporting of medical conditions compared with administrative medical data. ${ }^{32}$ Although we do not know the extent of underreporting, the fact that Census Bureau employees conducted the survey and that no financial incentive was offered for participation likely minimized any incentives to provide inaccurate information. Additionally, underreporting of medical conditions would strengthen our finding that pre-release older adults have more medical conditions than nonincarcerated older adults. Also, it is possible that some veterans in our sample failed to self-identify, while other respondents falsely identified themselves as veterans. Given that we found few differences between the two groups, this possibility is unlikely to have affected our findings. Finally, because this study was cross-sectional, we were unable to determine how many respondents actually experienced homelessness after reentry. Prospective studies are needed to assess rates of homelessness, medical decompensation, and mortality among older released prisoners.

To our knowledge, this is the first study describing the health status and homelessness risk for older pre-release prisoners. We found that such prisoners had high rates of medical conditions, serious mental illness, and risk of postrelease homelessness, regardless of veteran status. While national reentry planning programs for veterans are expanding, the overwhelming similarity in poor health status and homelessness risk between older veterans and non-veterans suggests that programs of equal breadth and caliber are needed for non-veteran older prisoners. 
Acknowledgements: Brie Williams was supported in part by the Brookdale Leadership in Aging Fellowship, the National Institute of Aging (K23AG033102), and the Hellman Family Award. Rebecca Lindsay was supported by the UCSF Dean's Summer Fellowship. Drs. Williams, McGuire, and Lee are employees of the Department of Veterans Affairs. The opinions expressed in this manuscript may not represent those of the VA.

We thank Leonard Pechacek for providing editing support and Karla Lindquist for help with data analysis.

Conflicts of Interest: Dr. Williams has been a consultant about prison conditions of confinement. These relationships did not affect the analysis or interpretation of the data or preparation of this manuscript.

Open Access: This article is distributed under the terms of the Creative Commons Attribution Noncommercial License which permits any noncommercial use, distribution, and reproduction in any medium, provided the original author(s) and source are credited.

Corresponding Author: Brie A. Williams, MD; Division of Geriatrics University of California, San Francisco, 4150 Clement Street, Box 181-G, San Francisco, CA 94121, USA (e-mail: brie.williams@ ucsf.edu).

Margot Kushel, MD; Division of General Internal Medicine, University of California, San Francisco, UCSF Box 1364, San Francisco, CA 94143-1364, USA (e-mail: mkushel@medsfgh.ucsf.edu).

\section{REFERENCES}

1. Pew Center on the States. One in 100: Behind Bars in America 2008 Available at: http://www.pewcenteronthestates.org/report_detail.aspx? id=35904. Accessed May 13, 2010.

2. Mitka M. Aging prisoners stressing health care system. JAMA. 2004;292 (4):423-4.

3. Aday R. Aging Prisoners: Crisis in American Corrections. Westport: Praeger Publishers; 2003.

4. West HC, Sabol WJ. Prison Inmates at Midyear 2008 - Statistical Tables. Washington: US Department of Justice; 2009. Available at: http://bjs ojp.usdoj.gov/index.cfm?ty=pbdetail\&iid=361. Accessed May 13, 2010.

5. Enders SR, Paterniti DA, Meyers FJ. An approach to develop effective health care decision making for women in prison. J Palliat Med. 2005;8 (2):432-9.

6. Report of the Re-entry Policy Council: Charting the Safe and Successful Return of Prisoners to the Community. New York: Council of State Governments; 2005.

7. Travis J, Solomon AL, Waul M. From Prison to Home: The Dimensions and Consequences of Prisoner Reentry. Washington: Urban Institute; 2001. Available at http://www.urban.org/publications/410098.html. Accessed May 13, 2010.

8. Wakeman SE, McKinney ME, Rich JD. Filling the gap: the importance of Medicaid continuity for former inmates. J Gen Intern Med. 2009;24 (7):860-862.

9. Aday R. Aging Prisoners: Crisis in American Corrections. Westport: Praeger Publishers; 2003.

10. La Vigne N, Davies E, Palmer T, Halberstadt R. Release Planning for Successful Reentry, A Guide for Corrections, Service Providers, and Community Groups. Urban Institute Publication. Sept 26, 2008. Available online at: http://www.urban.org/publications/411767.html. Accessed May 13, 2010.

11. Hughes T, Wilson DJ. Reentry Trends in the United States. Washington: US Department of Justice. Available at: http://bjs.ojp.usdoj.gov/index. cfm?ty=pbdetail\&iid=1138. Accessed May 13, 2010.

12. Langan PA, Levin DJ. Recidivism of prisoners released in 1994 Washington: US Department of Justice. Available at: http://bjs.ojp usdoj.gov/index.cfm?ty=pbdetail\&iid=1134. Accessed May 13, 2010.

13. Fazel S, Hope T, O'Donnell I, Piper M, Jacoby R. Health of elderly male prisoners: worse than the general population, worse than younger prisoners. Age Ageing. 2001;30(5):403-7.

14. Binswanger IA, Stern MF, Deyo RA, et al. Release from prison-a high risk of death for former inmates. N Engl J Med. 2007;356(2):157-65.
15. Burt MR, Aron LY, Douglas T, Valente J, Lee E, Iwen B. Homelessness: Programs and the People They Serve. Summary Report. Findings of the National Survey of Homeless Assistance Providers and Clients. Washington: Urban Institute; 1999

16. Fischer PJ. Criminal activity among the homeless: a study of arrests in Baltimore. Hosp Community Psychiatry. 1988;39(1):46-51.

17. Loeb SJ, Abudagga A. Health-related research on older inmates: an integrative review. Res Nurs Health. 2006;29(6):556-65.

18. Loeb SJ, Steffensmeier D, Myco PM. In their own words: older male prisoners' health beliefs and concerns for the future. Geriatr Nurs. 2007;28(5):319-29.

19. Hahn JA, Kushel MB, Bangsberg DR, Riley E, Moss AR. Brief report: The aging of the homeless population: 14-year trends in San Francisco. J Gen Intern Med. 2006;21(7):775-8

20. Hwang SW, Orav EJ, O'Connell JJ, Lebow JM, Brennan TA. Causes of death in homeless adults in Boston. Ann Intern Med. 1997;126(8):625-8.

21. Hwang Sw, Lebow JM, Bierer MF, O'Connell JJ, Orav EJ, Brennan TA. Risk factors for death in homeless adults in Boston. Arch Intern Med. 1998;158(13):1454-60.

22. Hwang SW, Tolomiczenko G, Kouyoumdjian FG, Garner RE. Interventions to improve the health of the homeless: a systematic review. Am J Prev Med. 2005;29(4):311-9.

23. Kushel MB, Vittinghoff E, Haas JS. Factors associated with the health care utilization of homeless persons. JAMA. 2001;285(2):200-6.

24. Rosenheck R, Seibyl CL. Homelessness: health service use and related costs. Med Care. 1998;36(8):1256-64.

25. Rosenheck R, Kizer KW. Hospitalizations and the homeless. N Engl J Med. 1998;339(16):1166.

26. Noonan ME, Mumola CJ. Veterans in State and Federal Prison, 2004 Bureau of Justice Statistics Special Report; No. NCJ 217199. Washington: US Department of Justice; 2007.

27. Gamache G, Rosenheck R, Tessler R. The proportion of veterans among homeless men: a decade later. Soc Psychiatry Psychiatr Epidemiol. 2001;36(10):481-5

28. McGuire J. Closing a front door to homelessness among veterans. J Prim Prev. 2007;28(3-4):389-400.

29. US Department of Veterans Affairs. Homeless Veterans: Health Care for Reentry Veterans Services and Resources. Available at: http://www1.va. gov/HOMELESS/Reentry.asp. Accessed May 13, 2010.

30. Lattimore PK. Prisoner reentry policy \& practice: lessons from the SVORI Multi-site Evaluation. Presented at the American Society of Criminology Annual Meeting, St. Louis, MO; November 11, 2008. Available at: https://www.svori-evaluation.org/documents/Presenta tions/2008_11_ASC_Policy.pdf. Accessed May 13, 2010.

31. National Archive of Criminal Justice Data. Survey of Inmates in State and Federal Correctional Facilities Resource Guide. Available at: http:// www.icpsr.umich.edu/NACJD/sisfcf/. Accessed May 13, 2010.

32. Maruschak LM, Beck AJ. Medical Problems of Inmates, 1997. January 2001. Bureau of Justice Statistics, US Department of Justice. Washington, DC. Available at: http://bjs.ojp.usdoj.gov/content/pub/pdf/mpi97. pdf. Accessed May 13, 2010.

33. Anno BJ, Graham C, Lawrence JE, Shansky R. Correctional Health Care: Addressing the Needs of Elderly, Chronically Ill, and Terminally Ill Inmates. Middletown: Criminal Justice Institute; 2004.

34. Baillargeon J, Black SA, Pulvino J, Dunn K. The disease profile of Texas prison inmates. Ann Epidemiol. 2000;10(2):74-80

35. Caverley SJ. Older Mentally Ill Inmates: A descriptive study. J Correct Health Care. 2006; 12(4):262-8.

36. Baillargeon J, Binswanger IA, Penn JV, Williams BA, Murray OJ. Psychiatric disorders and repeat incarcerations: the revolving prison door. Am J Psychiatry. 2009;166(1):103-9.

37. Bush TL, Miller SR, Golden AL, Hale WE. Self-report and medical record report agreement of selected medical conditions in the elderly. Am J Public Health. 1989;79(11):1554-6.

38. Covinsky KE, Palmer RM, Counsell SR, Pine ZM, Walter LC, Chren MM. Functional status before hospitalization in acutely ill older adults: validity and clinical importance of retrospective reports. J Am Geriatr Soc. 2000;48(2):164-9.

39. Kriegsman DM, Penninx BW, van Eijk JT, Boeke AJ, Deeg DJ. Selfreports and general practitioner information on the presence of chronic diseases in community dwelling elderly. A study on the accuracy of patients' self-reports and on determinants of inaccuracy. J Clin Epidemiol. 1996;49(12):1407-17.

40. Skinner KM, Miller DR, Lincoln E, Lee A, Kazis LE. Concordance between respondent self-reports and medical records for chronic condi- 
tions: experience from the Veterans Health Study. J Ambul Care Manage. 2005;28(2): 102-10.

41. Metraux S, Culhane DP. Homeless shelter use and reincarceration following prison release. Criminol Public Policy. 2004;3(2):201-22.

42. Tsai M, Weintraub R, Gee L, Kushel M. Identifying homelessness at an urban public hospital: a moving target? J Health Care Poor Underserved. 2005; 16(2):297-307.

43. Kushel MB, Gupta R, Gee L, Haas JS. Housing instability and food insecurity as barriers to health care among low-income Americans. J Gen Intern Med. 2006;21(1):71-7.

44. Cohen CI, Sokolovsky J, Crane M. Aging, homelessness, and the law. Int J Law Psychiatry. 2001;24(2-3):167-81.

45. Stergiopoulos V, Herrmann N. Old and homeless: A review and survey of older adults who use shelters in an urban setting. Can J Psychiatry. 2003;48(6):374-80.

46. US Department of Veterans Affairs. Federal Benefits for Veterans, Dependents, and Survivors. Washington: US Government Printing Office; 2009.

47. VA Health Care. Impact on eligibility for VA health care benefits. Fact Sheet 16-8. Available at: http://www4.va.gov/healtheligibility/Library/ pubs/OtherThanHonorable/OtherThanHonorable.pdf. Accessed May 13, 2010.

48. Simpson DD, Knight K, Broome KM. Texas Christian University/ Criminal Justice Forms Manual: Drug Dependence Screen and Initial Assessment. Fort Worth: Texas Christian University, Institute of Behavioral Research; 1997. Forms available at http://www.ibr.tcu.edu/pubs/ datacoll/cjtrt.html\#CorrScreeningforTreatment. Accessed May 13, 2010.

49. Ewing JA. Detecting alcoholism. The CAGE questionnaire. JAMA. 1984;252(14):1905-7.
50. Mallik-Kane K, Visher CA. Health and Prisoner Reentry: How Physical, Mental, and Substance Abuse Conditions Shape the Process of Reintegration. Washington: Urban Institute; 2008.

51. Schoenborn CA, Vickerie JL, Powell-Griner E. Health characteristics of adults 55 years of age and over: United States 2000-2003. Advance Data from Vital and Health Statistics; No 370. Hyattsville: National Center for Health Statistics 2006

52. Belcher JR. Are jails replacing the mental health system for the homeless mentally ill? Community Ment Health J. 1988;24(3):18595.

53. Kushel MB, Hahn JA, Evans JL, Bangsberg DR, Moss AR. Revolving doors: imprisonment among the homeless and marginally housed population. Am J Public Health. 2005;95(10):1747-52.

54. McGuire JF, Rosenheck RA. Criminal history as a prognostic indicator in the treatment of homeless people with severe mental illness. Psychiatr Serv. 2004;55(1):42-8.

55. Cohen CI. Aging and homelessness. Gerontologist. 1999;39(1):5-14

56. McGuire J. The Incarcerated Veterans Transition Program (IVTP): A Pilot Program Evaluation of IVTP Employment and Enrollment, VA Service Use and Criminal Recidivism. Washington, D.C. 2008.

57. McGuire J, Blue-Howells J. Fact Sheet: VA Services for Veterans being released from state and federal prisons: The VA Healthcare for Reentry Veterans (HCRV) Program. Department of Veterans Affairs. 2009.

58. Petersilia J. When Prisoners Come Home: Parole and Prisoner Reentry. New York: Oxford University Press; 2003.

59. US Department of Justice, National Institute of Justice. NIJ's Evaluation of the Serious and Violent Offender Reentry Initiative. Available at: http://www.ojp.usdoj.gov/nij/topics/corrections/reentry/evaluationsvori.htm Accessed May 13, 2010. 